\title{
GROUP III/IV MUSCLE AFFERENTS IMPAIR LIMB BLOOD IN PATIENTS WITH CHRONIC HEART FAILURE
}

\author{
Markus Amann ${ }^{1,2,3}$, Massimo Venturelli ${ }^{1}$, Stephen J. Ives ${ }^{3}$, David E. Morgan², Benjamin \\ Gmelch $^{2}$, Melissa A.H. Witman ${ }^{3}$, H. Jonathan Groot ${ }^{3}$, D. Walter Wray ${ }^{1,3}$, Josef Stehlik ${ }^{1}$, and \\ Russell S. Richardson ${ }^{1,3}$ \\ ${ }^{1}$ Department of Medicine, University of Utah, Salt Lake City, UT \\ ${ }^{2}$ Department of Anesthesiology, University of Utah, Salt Lake City, UT \\ ${ }^{3}$ Geriatric Research, Education, and Clinical Center, VAMC Salt Lake City, UT
}

\section{Abstract}

Objective-To better understand the hemodynamic and autonomic reflex abnormalities in heartfailure patients (HF), we investigated the influence of group III/IV muscle afferents on their cardiovascular response to rhythmic exercise.

\begin{abstract}
Methods-Nine HF-patients (NYHA class-II, mean left ventricular ejection-fraction: $27 \pm 3 \%$ ) performed single leg knee-extensor exercise (25/50/80\% peak-workload) under control conditions and with lumbar intrathecal fentanyl impairing $\mu$-opioid receptor-sensitive muscle afferents.

Results-Cardiac-output $(Q)$ and femoral blood-flow $\left(Q_{\mathrm{L}}\right)$ were determined, and arterial/venous blood samples collected at each workload. Exercise-induced fatigue was estimated via pre/postexercise changes in quadriceps strength. There were no hemodynamic differences between conditions at rest. During exercise, $Q$ was $8-13 \%$ lower with Fentanyl-blockade, secondary to significant reductions in stroke volume and heart rate. Lower norepinephrine spillover during exercise with Fentanyl revealed an attenuated sympathetic outflow that likely contributed to the $25 \%$ increase in leg vascular conductance $(\mathrm{p}<0.05)$. Despite a concomitant $4 \%$ reduction in blood pressure, $Q_{\mathrm{L}}$ was $10-14 \%$ higher and end-exercise fatigue attenuated by $30 \%$ with Fentanylblockade $(\mathrm{p}<0.05)$.
\end{abstract}

Conclusion/Practice/Implications-Although group III/IV muscle afferents play a critical role for central hemodynamics in HF-patients, it also appears that these sensory neurons cause

\footnotetext{
(c) 2014 Elsevier Ireland Ltd. All rights reserved.

Corresponding Author: Markus Amann, VA Medical Center, 500 Foothill Drive, GRECC 182, Salt Lake City, UT 84148, USA, markus.amann@ hsc.utah.edu, Phone: 801 582-1565 ext. 4358, Fax: 801 584-5658.

All authors take responsibility for all aspects of the reliability and freedom from bias of the data presented and their discussed interpretation.
}

\section{DISCLOSURES}

None.

Publisher's Disclaimer: This is a PDF file of an unedited manuscript that has been accepted for publication. As a service to our customers we are providing this early version of the manuscript. The manuscript will undergo copyediting, typesetting, and review of the resulting proof before it is published in its final citable form. Please note that during the production process errors may be discovered which could affect the content, and all legal disclaimers that apply to the journal pertain. 
excessive sympatho-excitation impairing $Q_{\mathrm{L}}$ which likely contributes to the exercise intolerance in this population.

\section{Keywords}

circulation; exercise pressor reflex; sensory neurons; autonomic control

\section{INTRODUCTION}

With the onset of physical activity, contraction-induced mechanical and chemical stimuli increase the spontaneous discharge of both thinly myelinated (group III) and unmyelinated (group IV) nerve fibers located within skeletal muscle ${ }^{1}$. These thin fiber muscle afferents project to various sites within the brainstem and reflexly evoke increases in ventilation and sympathetic outflow to the heart and peripheral vasculature stimulating circulation ${ }^{2}$. In conjunction with central command mechanisms ${ }^{3}$, these muscle reflexes determine the cardioventilatory response to exercise and thereby ensure a match between $\mathrm{O}_{2}$ demand and supply in working skeletal muscle.

A series of studies have recently provided novel insight into the contribution of group III/IV muscle afferents to the ventilatory and circulatory responses to dynamic exercise in humans ${ }^{4-6}$. By using lumbar intrathecal fentanyl, a selective $\mu$-opioid receptor agonist, the central projection of group III/IV muscle afferents were inhibited during exercise without affecting muscle force generating capacity and central command. Partially blocking these sensory fibers during aerobic exercise over a wide range of intensities caused a substantial reduction in central [cardiac output $(Q)$, heart rate (HR), stroke volume (SV), blood pressure] and peripheral hemodynamics $\left(Q_{L}\right)$ and decreased locomotor muscle $\mathrm{O}_{2}$ delivery. Conservative estimates suggest that group III/IV muscle afferents might account for between 20 to $50 \%$ of the circulatory and ventilatory responses to exercise in healthy humans 4,5 .

Patients with heart failure (HF) are characterized by muscle reflex abnormalities ${ }^{7-9}$ with exaggerated afferent feedback as the likely underlying mechanism ${ }^{10-12}$. However, it has been argued that the pronounced afferent feedback might be somewhat beneficial in facilitating central hemodynamics and maintaining arterial pressure during exercise in $\mathrm{HF}^{13}$. Although exaggerated afferent feedback may actually be of benefit in the early stages of impaired myocardial function, the chronic excessive sympathoexcitation associated with the progression of the disease is likely detrimental ${ }^{10}$. The latter causes exaggerated peripheral vasoconstriction and group III/IV muscle afferents might thereby, in contrast to their role in healthy individuals ${ }^{4}$, compromise $Q_{L}$ during exercise in HF. Indeed, compared to their healthy counterparts, $Q_{L}$ in patients with HF has been documented to be attenuated during exercise in humans ${ }^{14}$ as well as animals ${ }^{15}$. However, it is also possible that the impaired $Q_{L}$ during exercise in HF may be independent of altered neural feedback from working limb muscle. Specifically, impaired endothelial dependent vasodilator function 16 and other disease-related alterations in skeletal muscle ${ }^{17,18}$ might account, at least in part, for the compromised peripheral hemodynamics in HF.

Consequently, we aimed to evaluate the role of group III/IV muscle afferents in determining the cardiovascular response to rhythmic exercise in patients with HF. Based on our previous 
findings ${ }^{4-6}$, we hypothesized that reducing such feedback would attenuate the increase in $Q$ in patients with HF. In contrast to this beneficial role of locomotor muscle afferents, we hypothesized that the excessive afferent-mediated muscle sympathoexcitation associated with HF results in inappropriate peripheral vasoconstriction and thus pharmacological blockade of this feedback would facilitate an increase in $Q_{L}$ in patients with HF, but not in well-matched healthy control subjects (Healthy-Ctrl). Finally, we hypothesized that this increase in $Q_{L}$ would attenuate exercise-induced quadriceps fatigue in $\mathrm{HF}$, helping to explain the exercise intolerance that characterizes this population.

\section{METHODS}

\section{Subjects}

Nine male patients with HF and nine Healthy-Ctrls volunteered for this study (Table 1). Written informed consent was obtained from each participant and all procedures were approved by the Institutional Review Boards of the University of Utah and the Salt Lake City VA Medical Center.

\section{Protocol}

Participants were thoroughly familiarized with all procedures in 3 sessions. On the experimental day, subjects returned to the laboratory where their right femoral artery and vein were catheterized as previously described ${ }^{4}$. Following a 30-min rest period, resting $\mathrm{CO}_{2}$ sensitivity was evaluated by the ventilatory response to three levels of inspiratory $\mathrm{CO}_{2}$ $\left(\mathrm{F}_{\mathrm{I}} \mathrm{CO}_{2}\right)$. Following a short break, control (Ctrl) baseline values for cardiovascular variables were collected and resting arterial/venous blood samples were taken. The Ctrl exercise trial consisted of 3 consecutive levels of constant-load right leg knee-extensor exercise (3-min each, $60 \mathrm{rev} / \mathrm{min})$ performed at $25(7 \mathrm{~W}), 50(14 \mathrm{~W})$ and $80 \%(22 \mathrm{~W})$ of the patients' peak workload $\left(\mathrm{W}_{\text {peak }}\right)$, determined during the practice trials. Healthy-Ctrls performed two absolute $(7 \mathrm{~W}$ and $14 \mathrm{~W})$, and two relative $\left(50 \%\right.$ and $\left.80 \% \mathrm{~W}_{\text {peak }}\right)$ workloads for 3-min each. Central and peripheral hemodynamics were recorded continuously while arterial and venous blood samples were taken during the final minute of each workload. Following a 2-hour rest period, and after verifying that resting $Q_{L}$ and maximal voluntary quadriceps contraction (MVC) had returned to pre-exercise baseline values, intrathecal fentanyl $(0.025 \mathrm{mg} / \mathrm{ml})$ was delivered at vertebral interspace L3-L4 ${ }^{19}$. To minimize the potential risk of cephalic movement of fentanyl within the cerebral spinal fluid (CSF), subjects remained in the upright seated position throughout the remainder of the study. Cutaneous hypoaesthesia to pinprick and cold perception on the torso and upper limbs were examined prior to exercise. Approximately $20 \mathrm{~min}$ post fentanyl injection, the steady-state $\mathrm{CO}_{2}$ sensitivity test, baseline measures, and knee-extensor exercise protocol were repeated. Following both the Ctrl and fentanyl trial, exercise-induced quadriceps fatigue was estimated in the patient group (see below). The investigator performing all data analyses was blinded to the experimental condition.

\section{Measurements}

$\mathbf{Q}_{\mathbf{L}}$-Simultaneous measurements of common femoral arterial blood velocity $\left(\mathrm{V}_{\text {mean }}\right)$ and vessel diameter were performed distal to the inguinal ligament and proximal to the 
bifurcation of the deep and superficial femoral arteries with a Logic 7 ultrasound system (General Electric). Using arterial diameter and $\mathrm{V}_{\text {mean }}, Q_{L}$ was calculated as: $\mathrm{V}_{\text {mean }} \cdot \pi$. $(\text { vessel diameter } / 2)^{2} \cdot 60$.

Ventilatory and Cardiovascular Responses-Ventilation during the $\mathrm{CO}_{2}$ response test was measured continuously (Parvo Medics, True Max 2400). HR was measured from the R-R interval using a 3-lead electrocardiogram (Biopac). Stroke volume (SV) was estimated from beat-by-beat pressure waveforms assessed by photoplethysmography. This method has previously been documented to accurately reflect relative changes in SV in health and disease ${ }^{20}$. However, as this method has not been validated in patients with HF, data collected in this manner should be interpreted with caution. $Q$ was calculated as SV x HR. Arterial and venous blood pressure measurements were collected continuously from within the femoral artery and vein, with pressure transducers placed at the level of the catheters. Mean arterial pressure (MAP) was calculated as MAP=DP+1/3(SP-DP) while mean venous $(\mathrm{MVP})$ was calculated as $\mathrm{MVP}=(\mathrm{SP}+\mathrm{DP}) / 2$. Leg vascular conductance $(\mathrm{LVC})$ was calculated as $Q_{L} /(\mathrm{MAP}-\mathrm{MVP})$.

Blood Derived Variables-Blood samples were collected anaerobically and analyzed by a combined blood gas and co-oximeter sytem (GEM 4000). Various blood-derived variables, including plasma norepinephrine (NE) and epinephrine concentrations/spillover, were measured as previously described ${ }^{4}$.

Steady-State $\mathbf{C O}_{2}$-Sensitivity Test-In addition to eupneic air breathing (5 minutes), ventilatory responses to two concentrations of $\mathrm{CO}_{2}$ (steady-state, open circuit; $70 \% \mathrm{O}_{2}, 3$ and $6 \% \mathrm{CO}_{2}$, balance $\mathrm{N}_{2}$ ) were assessed for 4 minutes punctuated by at least 5 minutes of exposure to room-air ${ }^{4}$. Arterial blood gases were collected during the final 30 -seconds of each condition.

Quadriceps Fatigue-Knee joint angle of the right leg was set at $90^{\circ}$ flexion and patients maximally contracted their quadriceps for 3 seconds. Quadriceps MVC force was obtained from a calibrated load cell connected to a noncompliant strap placed around the subject's right leg (ankle malleoli). The assessment procedure was performed before (5min) and $1 \mathrm{~min}$ after each of the two exercise trials.

\section{Statistical Analysis}

A two-way analysis of variance with repeated measures was performed to evaluate differences between trials. A least significance difference test identified the means that were significantly different with $\mathrm{p}<0.05$. Results are expressed as the mean \pm SEM.

\section{RESULTS}

\section{Resting Ventilatory Responses to $\mathrm{CO}_{2}$ and Cutaneous Hypoaesthesia}

Eupneic air breathing was not altered from Ctrl by fentanyl-blockade, as indicated by the nearly identical breathing pattern and similar $\mathrm{P}_{\mathrm{a}} \mathrm{CO}_{2}$ values in all subjects (Table 2). Exposure to the two levels of increased $\mathrm{F}_{\mathrm{I}} \mathrm{CO}_{2}$ resulted in similar $\mathrm{P}_{\mathrm{a}} \mathrm{CO}_{2}$ values and 
subsequently hypercapnic ventilatory responses in both conditions and in both groups. Neurological examinations just prior to the start of the exercise revealed cutaneous hypoaesthesia to pinprick and cold perception. This was evident by sensory changes on the torso at, or below, T5/T6 and by the absence of sensory changes on the upper limbs.

\section{Central Hemodynamic Responses (Figure 1)}

At rest, $\mathrm{HR}, \mathrm{SV}, Q$ and MAP were similar in Ctrl and with fentanyl-blockade. Compared to Ctrl exercise, HR was 2-5\% lower in HF ( $\mathrm{p}=0.047)$ and up to 7\% lower in Healthy-Ctrls $(\mathrm{p}=0.012)$ across various intensities with fentanyl-blockade. Under Ctrl conditions in HF, $\mathrm{SV}$ rose significantly from rest to the first level of exercise, but remained unchanged with further increases in workload. In contrast, SV did not change from rest with fentanylblockade and this resulted in a 12-14\% lower SV compared to Ctrl. In Healthy-Ctrls, fentanyl-blockade had no effect on SV. Fentanyl had a significant main effect on the exercise-induced change in $Q$ in HF as illustrated by an $8-13 \%$ lower response compared to Ctrl. In Healthy-Ctrls, fentanyl-blockade did not significantly alter the $Q$-response to exercise. MAP was consistently 3-5\% lower during exercise with fentanyl-blockade in HF and this reduction was significant at 50 and $80 \% \mathrm{~W}_{\text {peak }}$. In Healthy-Ctrls, Fentanyl had a significant main effect on MAP with a consistent 4-5\% reduction across workloads. MVP increased similarly and significantly from rest to exercise in both conditions and both groups.

\section{Peripheral Hemodynamic Responses (Table 3, Figure 2)}

At rest, $Q_{L}$, NE spillover, and LVC were similar in both the Ctrl and the fentanyl trial (all $\mathrm{p}>0.3$ ) and increased significantly from rest to exercise in both conditions. However, during exercise, fentanyl-blockade had a significant main effect on $Q_{L}$ and LVC which was reflected in a 10-14\% and 23-26\% increase, respectively, across all workloads. Compared to $\mathrm{Ctrl}$, fentanyl-blockade had a significant main effect on NE spillover ( $\mathrm{p}=0.031)$ resulting in an 18-25\% reduction during exercise. This difference reached statistical significance at 25 and $50 \%$ of $\mathrm{W}_{\text {peak }}$. In Healthy-Ctrls, although similar at rest, fentanyl-blockade had a significant main effect on LVC during exercise, resulting in a 4-10\% increase. However, fentanyl-blockade had no effect on $Q_{L}$ during exercise in this group.

\section{Leg $\mathrm{O}_{2}$ Supply and $\mathrm{O}_{2}$ Utilization (Figure 3, Table 3)}

At rest, $\mathrm{O}_{2}$ delivery $(\sim 0.04 \mathrm{l} / \mathrm{min})$, arteriovenous $\mathrm{O}_{2}$ difference $(\sim 90 \mathrm{ml} / \mathrm{l})$ and leg $\mathrm{VO}_{2}$ $(\sim 0.02 \mathrm{l} / \mathrm{min}$ ) were similar in both conditions in $\mathrm{HF}$ (all $\mathrm{p}>0.4) . \mathrm{O}_{2}$ delivery was $8-14 \%$ higher throughout exercise with fentanyl-blockade and this difference achieved statistical significance at each workload. Despite a lack of effect of fentanyl-blockade on $\mathrm{C}_{\mathrm{a}} \mathrm{O}_{2}$ during exercise, $\mathrm{C}_{\mathrm{v}} \mathrm{O}_{2}$ was, on average, $\sim 6 \%$ lower. Consequently, leg $\mathrm{VO}_{2}$ during exercise was 10-17\% higher in the fentanyl trial compared to Ctrl ( $\mathrm{p}<0.05)$. In Healthy-Ctrls, fentanyl had no effect $\mathrm{O}_{2}$ delivery, arteriovenous $\mathrm{O}_{2}$ difference, and leg $\mathrm{VO}_{2}$ at rest. Although leg $\mathrm{O}_{2}$ delivery during exercise was also unchanged with fentanyl, the arteriovenous $\mathrm{O}_{2}$ difference was again 3-7\% higher compared to $\mathrm{Ctrl}$ and this was reflected by a significant main effect of Fentanyl on leg $\mathrm{VO}_{2}$, resulting in a $7-13 \%$ increase. 


\section{Rating of Perceived Exertion (RPE) and Exercise-Induced Quadriceps Fatigue in HF (Fig. 4)}

Pre-exercise baseline MVCs were similar for the Ctrl and the fentanyl trial $(370 \pm 13 \mathrm{~N}$ vs $367 \pm 13 \mathrm{~N}$, respectively, $\mathrm{p}=0.6$ ). The exercise-induced decrease in quadriceps $\mathrm{MVC}$ ranged from $-40 \%$ to $-12 \%$ and from $-30 \%$ to $-8 \%$ for the Ctrl and the fentanyl condition, respectively. Fentanyl had a significant main effect on RPE during exercise with post-hoc analyses revealing significance at 50 and $80 \%$ of $\mathrm{W}_{\text {peak }}(-23 \pm 6 \%$ and $-25 \pm 5 \%$, respectively). RPE was not affected by Fentanyl in Healthy-Ctrls ( $\mathrm{P}=0.5)$.

\section{DISCUSSION}

Lumbar intrathecal fentanyl was used to temporarily attenuate $\mu$-opioid receptor-sensitive group III/IV muscle afferent feedback at rest and during graded rhythmic exercise to determine the impact of this feedback on central and peripheral hemodynamics in patients with HF and Healthy-Ctrls. Although there was no effect of the spinal blockade at rest, our data suggest a critical role of these thin-fiber afferents in the circulatory control during exercise. Specifically, with HF, in the absence of neural feedback from the lower limb, the exercise-induced increase in $Q$ and blood pressure was significantly attenuated compared to control exercise. Furthermore, NE spillover was lower during exercise with partially blocked muscle afferents and the associated increase in LVC led to up to a $15 \%$ increase in $Q_{L}$ and leg $\mathrm{O}_{2}$ delivery and uptake which likely contributed to the observed $30 \%$ attenuation of endexercise quadriceps fatigue and reduced effort perception in these conditions. In contrast, in Healthy-Ctrls, despite similar decreases in perfusion pressure following afferent blockade, the concomitant increase in LVC was less than half of that observed in $\mathrm{HF}$ and $Q_{L}$ remained unchanged from control exercise. Taken together, these findings reveal that group III/IV muscle afferents appear to contribute to the appropriate exercise-induced cardiac response in patients with HF. Perhaps most importantly however, this study shows that such feedback, previously documented to be overactive in HF, appears to result in an excessive sympathetically-mediated restraint of $Q_{L}$ during exercise in these patients, an effect not observed in Healthy-Ctrls. This attenuation of $Q_{L}$ and the subsequent reduction in $\mathrm{O}_{2}$ delivery and uptake likely contribute to the compromised fatigue resistance and associated exercise intolerance which characterize this population.

\section{Temporary Spinal Blockade of Group III/IV Lower Limb Muscle Afferents}

Central projections of lower limb muscle afferents synapse on cells in laminae I and V of the lumbar dorsal horn of the spinal cord. These dorsal horn cells project to the ventral lateral medulla and the nucleus tractus solitarii where they influence breathing and cardiovascular control. The stimulation of spinal opioid-receptors with the selective $\mu$-opioid receptor agonist fentanyl inhibits group III/IV mediated input to the spinal cord without affecting motor nerve function ${ }^{5,19}$, sympathetic efferent neurotransmission $5,21,22$, or central motor drive during a given submaximal/non-exhaustive trial ${ }^{5,6}$. It is important to recognize that this approach only partially blocks group III/IV muscle afferent feedback, namely, those fibers mediated by $\mu$-opioid receptors. This temporary local blockade of afferent feedback has previously been documented to reduce circulatory and ventilatory responses to exercise in healthy humans ${ }^{4-6}$ and animals ${ }^{23}$. As fentanyl itself can compromise cardiovascular and ventilatory control with cephalad spread from the intrathecal injection site, individual 
neurological examinations and hypercapnic ventilatory response tests $\sim 20$ min following fentanyl delivery were performed in all subjects. Based on lack of an effect of fentanyl on these tests, a direct medullary impact in any of our subjects was excluded. Taken together, it can be safely assumed that the exercise with fentanyl was, compared to the control trial, characterized by similar central motor drive, similar sympathetic efferent neurotransmission, and the absence of a direct effect of fentanyl on brain opioid receptors - but by attenuated group III/IV-mediated afferent feedback from the lower limb.

\section{Muscle Afferents and Central Hemodynamics during Exercise in HF}

Thin fiber muscle afferents from the exercising limb evoke inotropic and chronotropic effects on the heart to increase $Q$ in exercising animals ${ }^{24}$ and humans ${ }^{25}$. Specifically, these sensory neurons appear to reflexively increase $\mathrm{HR}^{24}$ and maintain or increase right atrial pressure ${ }^{26}$ and ventricular contractility ${ }^{24}$ during exercise. Utilizing the same afferent blocking technique in healthy young humans, we have recently documented that $20 \%$ of the $Q$ response to exercise can be accounted for by the substantial facilitating effects of group III/IV muscle afferent feedback on HR and SV ${ }^{4}$. The $\sim 12 \%$ lower $Q$ response with fentanyl-blockade in HF in the present study suggests that neural feedback remains a significant determinant during dynamic exercise in such patients. However, this mechanism may be somewhat attenuated compared to young individuals, mainly due to the limited effect of the muscle afferents on the patients' HR. Nevertheless, the significant influence of muscle afferents on the $Q$ response to exercise in healthy young individuals ${ }^{4}$ and in patients with HF is in contrast to the older Healthy-Ctrls studied here (Figure-1), who were characterized by a lack of an influence of fentanyl-blockade on the overall $Q$ response. Interestingly, this potentially age-related diminished effect of group III/IV muscle afferents appears to be partially reversed with HF. Specifically, in contrast to previous canine studies ${ }^{27}$, our current observations suggest that HF in humans might increase, compared to Healthy-Ctrls, the influence of group III/IV muscle afferents on ventricular function via their facilitating effects on myocardial contractility.

It should be noted that in both our previous study in healthy subjects ${ }^{4}$ and the current work, potential differences in venous return that may have lowered SV and ultimately attenuated $Q$ during exercise with fentanyl compared to control exercise cannot be excluded. The fact that all patients with HF in this study were treated with beta blockers adds an additional layer of complexity in terms of data interpretation, specifically in terms of central hemodynamic regulation and other reflex responses during exercise. Hence, the required increase in HR in the face of an attenuated SV may have been blunted, possibly also compromising the $Q$ response. However, as HR was typically well below $100 \mathrm{bpm}$, even during exercise (Figure-1), the sympathetic component of the drive to increase HR, and therefore the impact of beta blockade, was likely minimal.

\section{Muscle Afferents Limit $Q_{L}$ in HF}

Patients with $\mathrm{HF}$ are, compared to healthy individuals, characterized by higher muscle sympathetic nerve activity ${ }^{10}$ and a lower $Q_{\mathrm{L}}{ }^{14}$ during exercise. Reflex-mediated peripheral vasoconstriction has previously been suggested as the pathophysiological basis of this impairment and the present findings provide evidence for this hypothesis in humans. 
Specifically, the temporary and partial blockade of group III/IV muscle afferents increased vascular conductance to a greater degree in HF compared to Healthy-Ctrls, facilitating a significant increase in $Q_{\mathrm{L}}$ in the patients, but not in the Healthy-Ctrls. Indeed, as illustrated in Figure 2, the role of these neurons in determining the peripheral hemodynamic abnormalities characteristic of patients with HF appear to be quite considerable. Mechanistically, the lower NE spillover during the exercise with fentanyl-blockade suggests that the restraint in $Q_{\mathrm{L}}$ might, at least in part, be mediated by a-adrenergic vasoconstriction secondary to muscle afferent feedback. Although the NE spillover approach utilized here was able to reveal a potential link between muscle afferent feedback and catecholamine release, it should be recognized that there are limitations with this method, not the least of which is inherent variability. Interestingly, in patients with HF, it appears that the potentially positive effect of afferent feedback on the heart (i.e. stimulating $Q$ ) may be outweighed by the effect of increasing vasoconstrictor outflow which ultimately reduces $Q_{\mathrm{L}}$ and oxygen delivery to the periphery. This clearly contrasts with our current findings in Healthy-Ctrls (Figure 2) and our previous work in healthy young subjects ${ }^{4}$, in whom blocking afferent feedback resulted in either unchanged or diminished $Q_{\mathrm{L}}$, respectively.

Although a-adrenergic vasoconstriction secondary to muscle afferent feedback, identified here as a possible mechanism responsible of $Q_{\mathrm{L}}$ limitation in $\mathrm{HF}$, may play a significant role in this population, a variety of other potential contributors have previously been identified. For example, the tonic restraint of vasoconstrictor outflow by the arterial baroreflex was documented to be attenuated in $\mathrm{HF}^{28}$. Also related to the baroreflex, earlier canine experiments demonstrated that attenuated arterial baroreflex buffering of the muscle metaboreflex might account for some of the heightened sympathetic outflow and compromised $Q_{\mathrm{L}}$ in $\mathrm{HF}^{29}$. Furthermore, previous findings in humans suggest that the sensitized chemoreflex control of muscle sympathetic nerve activity ${ }^{30}$ in patients with HF might partly account for the attenuated vascular conductance and $Q_{\mathrm{L}}$ in this population ${ }^{31}$. It might also, simply, be argued that the a-adrenergic component of the sympathetic nervous system is over-sensitized in these patients. This would result in a more pronounced vasoconstriction and $Q_{\mathrm{L}}$ limitation in response to a given a-adrenoreceptor stimulus. Nevertheless, existing evidence contradicts this theory and suggests that vascular responsiveness to a-adrenoreceptor agonists is similar in HF and health, at least at rest ${ }^{32}$. Finally, muscle afferent feedback has also been associated with substantial increases in circulating levels of vasoactive hormones ${ }^{33}$. Therefore, our observation of an increase in $Q_{\mathrm{L}}$ following afferent blockade might, at least in part, be explained by a transient reduction in the plasma concentration of specific vasoactive substances such as, for example, renin or vasopressin.

\section{Impact of Group III/IV Muscle Afferents on Fatigue in HF}

The rate of development of locomotor muscle fatigue during exercise is critically dependent on $\mathrm{O}_{2}$ delivery and uptake. Specifically, increases in muscle $\mathrm{O}_{2}$ delivery attenuate while reductions in $\mathrm{O}_{2}$ delivery exacerbate peripheral fatigue ${ }^{34}$ which, per se, is positively related to increases in central fatigue, perceived exertion, and, importantly, exercise intolerance at submaximal intensities ${ }^{35}$. In this study, the increase in $Q_{\mathrm{L}}$, limb $\mathrm{O}_{2}$ delivery and uptake following afferent blockade in patients with HF resulted in a significant reduction in the 
rating of perceived exertion and an attenuated exercise-induced decrease in quadriceps strength (Figure 4). These findings highlight group III/IV muscle afferents as a critical determinant of the compromised fatigue resistance and exercise intolerance characterizing patients with $\mathrm{HF}$ and pinpoint the impact of these sensory neurons on muscle $\mathrm{O}_{2}$ delivery as the likely mechanistic link ${ }^{36}$. Interestingly, however, it was previously suggested that dobutamine-induced increases in central and peripheral hemodynamics and leg $\mathrm{O}_{2}$ uptake during bike exercise in patients with HF do not allow for an increase in the patients' maximal aerobic capacity 37,38 . Unfortunately, these studies did not investigate the consequence of the drug-induced hemodynamic improvements on low intensity endurance capacity (i.e. potential prolongation of time to exhaustion at a submaximal workload); this would have had a more functional relevance for the patients.

It should be noted that exercise-induced muscle fatigue in the present study was estimated via pre- to post-exercise changes in quadriceps MVC. As the magnitude of an MVC depends on both a peripheral (within the muscle) and central (motor drive) component, the current data offer no insight into the exact influence that muscle afferent feedback has on the development of each of the two elements of exercise-induced fatigue in patients with HF.

\section{Partitioning the Contribution of Group III- and IV-Mediated Afferent Feedback}

Although there is general agreement that an overactive mechanoreflex (mainly group III mediated) is a significant determinant of the exaggerated cardioventilatory responses to exercise in humans with HF, controversy exists regarding the contribution of the metaboreflex (mainly group IV mediated) to these abnormalities. Indeed, some studies have documented an overactive metaboreflex suggesting sensitized group IV muscle afferents in patients with $\mathrm{HF}^{11}$, while others have found an attenuated response, suggesting desensitized group IV afferents compared to Healthy-Ctrls ${ }^{12}$. The animal literature is more congruent and consistently indicates that the exaggerated cardiovascular responses in HF is mediated by enhanced group III muscle afferents, with the contribution from the group IV afferents documented to be blunted 39,40 . As the pharmacological approach utilized in this study nonspecifically attenuates both group III and IV muscle afferent feedback, unfortunately, it is not possible to partition the role of mechanoreflex and metaboreflex in the current findings.

\section{Conclusion}

Although, in contrast to well matched Healthy-Ctrls, group III/IV muscle afferent feedback plays a positive role in the central hemodynamic response to exercise in HF, it appears that these sensory neurons may also cause excessive sympatho-excitation which impairs $Q_{\mathrm{L}}$. This attenuation of $Q_{L}$ and the subsequent reduction in $\mathrm{O}_{2}$ delivery likely contribute to the compromised fatigue resistance and associated exercise intolerance which characterizes patients with HF.

\section{Acknowledgments}

Grant support: This work was supported by the US National Heart, Lung, and Blood Institute (HL-116579 and HL-103786 to Amann and HL-09183 to Richardson) and a VA Merit Grant (E6910R to Richardson). 
We thank Mr. Van R. Reese and Mrs. Jia Zhao for valuable assistance with the blood analyses, and Mary Beth Hagan, FNP and Robin Waxman, APRN from the Salt Lake City VAMC Heart Failure and Heart Transplant Clinic for their invaluable help with subject coordination.

\section{References}

1. Adreani CM, Hill JM, Kaufman MP. Responses of group iii and iv muscle afferents to dynamic exercise. J Appl Physiol. 1997; 82:1811-1817. [PubMed: 9173945]

2. Murphy MN, Mizuno M, Mitchell JH, Smith SA. Cardiovascular regulation by skeletal muscle reflexes in health and disease. American journal of physiology. Heart and circulatory physiology. 2011; 301:H1191-1204. [PubMed: 21841019]

3. Waldrop, TG.; Eldridge, FL.; Iwamoto, GA.; Mitchell, JH. Central neural control of respiration and circulation during exercise. In: Rowell, LB.; Shepherd, JT., editors. Handbook of physiology section 12: Exercise: Regulation and integration of multiple systems. New York: Oxford University Press; 1996. p. 333-380.

4. Amann M, Runnels S, Morgan DE, Trinity JD, Fjeldstad AS, Wray DW, Reese VR, Richardson RS. On the contribution of group iii and iv muscle afferents to the circulatory response to rhythmic exercise in humans. The Journal of physiology. 2011; 589:3855-3866. [PubMed: 21646407]

5. Amann M, Blain GM, Proctor LT, Sebranek JJ, Pegelow DF, Dempsey JA. Group iii and iv muscle afferents contribute to ventilatory and cardiovascular response to rhythmic exercise in humans. J Appl Physiol. 2010; 109:966-976. [PubMed: 20634355]

6. Amann M, Blain GM, Proctor LT, Sebranek JJ, Pegelow DF, Dempsey JA. Implications of group iii and iv muscle afferents for high intensity endurance exercise performance in humans. The Journal of physiology. 2011; 589:5299-5309. [PubMed: 21878520]

7. Piepoli MF, Dimopoulos K, Concu A, Crisafulli A. Cardiovascular and ventilatory control during exercise in chronic heart failure: Role of muscle reflexes. Int J Cardiol. 2008; 130:3-10. [PubMed: 18584895]

8. Garry MG. Abnormalities of the exercise pressor reflex in heart failure. Exerc Sport Sci Rev. 2011; 39:167-176. [PubMed: 21799426]

9. Olson TP, Joyner MJ, Johnson BD. Influence of locomotor muscle metaboreceptor stimulation on the ventilatory response to exercise in heart failure. Circ Heart Fail. 2010; 3:212-219. [PubMed: 20061520]

10. Notarius CF, Atchison DJ, Floras JS. Impact of heart failure and exercise capacity on sympathetic response to handgrip exercise. American journal of physiology. Heart and circulatory physiology. 2001; 280:H969-976. [PubMed: 11179037]

11. Piepoli MF, Coats AJ. Increased metaboreceptor stimulation explains the exaggerated exercise pressor reflex seen in heart failure. J Appl Physiol. 2007; 102:494-496. discussion 496-497. [PubMed: 17209160]

12. Middlekauff HR, Sinoway LI. Increased mechanoreceptor stimulation explains the exaggerated exercise pressor reflex seen in heart failure. J Appl Physiol. 2007; 102:492-494. discussion 496. [PubMed: 16990501]

13. Vanhoutte PM. Adjustments in the peripheral circulation in chronic heart failure. Eur Heart J. 1983; 4 (Suppl A):67-83. [PubMed: 6840124]

14. Sullivan MJ, Knight JD, Higginbotham MB, Cobb FR. Relation between central and peripheral hemodynamics during exercise in patients with chronic heart failure. Muscle blood flow is reduced with maintenance of arterial perfusion pressure. Circulation. 1989; 80:769-781. [PubMed: 2791242]

15. Hammond RL, Augustyniak RA, Rossi NF, Lapanowski K, Dunbar JC, O'Leary DS. Alteration of humoral and peripheral vascular responses during graded exercise in heart failure. J Appl Physiol. 2001; 90:55-61. [PubMed: 11133893]

16. Klosinska M, Rudzinski T, Grzelak P, Stefanczyk L, Drozdz J, Krzeminska-Pakula M. Endothelium-dependent and -independent vasodilation is more attenuated in ischaemic than in non-ischaemic heart failure. Eur J Heart Fail. 2009; 11:765-770. [PubMed: 19578078] 
17. Rehn TA, Munkvik M, Lunde PK, Sjaastad I, Sejersted OM. Intrinsic skeletal muscle alterations in chronic heart failure patients: A disease-specific myopathy or a result of deconditioning? Heart Fail Rev. 2012; 17:421-436. [PubMed: 21996779]

18. Okita K, Kinugawa S, Tsutsui H. Exercise intolerance in chronic heart failure--skeletal muscle dysfunction and potential therapies. Circulation journal : official journal of the Japanese Circulation Society. 2013; 77:293-300. [PubMed: 23337207]

19. Amann M, Proctor LT, Sebranek JJ, Pegelow DF, Dempsey JA. Opioid-mediated muscle afferents inhibit central motor drive and limit peripheral muscle fatigue development in humans. The Journal of physiology. 2009; 587:271-283. [PubMed: 19015193]

20. Bos WJ, Imholz BP, van Goudoever J, Wesseling KH, van Montfrans GA. The reliability of noninvasive continuous finger blood pressure measurement in patients with both hypertension and vascular disease. Am J Hypertens. 1992; 5:529-535. [PubMed: 1388963]

21. Nagasaka H, Yaksh TL. Effects of intrathecal mu, delta, and kappa agonists on thermally evoked cardiovascular and nociceptive reflexes in halothane-anesthetized rats. Anesth Analg. 1995; 80:437-443. [PubMed: 7864404]

22. Gaumann DM, Yaksh TL, Tyce GM. Effects of intrathecal morphine, clonidine, and midazolam on the somato-sympathoadrenal reflex response in halothane-anesthetized cats. Anesthesiology. 1990; 73:425-432. [PubMed: 2393126]

23. Hill JM, Kaufman MP. Attenuation of reflex pressor and ventilatory responses to static muscular contraction by intrathecal opioids. J Appl Physiol. 1990; 68:2466-2472. [PubMed: 2384427]

24. O'Leary DS, Augustyniak RA. Muscle metaboreflex increases ventricular performance in conscious dogs. Am J Physiol. 1998; 275:H220-224. [PubMed: 9688917]

25. Boushel R. Muscle metaboreflex control of the circulation during exercise. Acta physiologica. 2010; 199:367-383. [PubMed: 20353495]

26. Sheriff DD, Augustyniak RA, O'Leary DS. Muscle chemoreflex-induced increases in right atrial pressure. Am J Physiol. 1998; 275:H767-775. [PubMed: 9724278]

27. O'Leary DS, Sala-Mercado JA, Augustyniak RA, Hammond RL, Rossi NF, Ansorge EJ. Impaired muscle metaboreflex-induced increases in ventricular function in heart failure. American journal of physiology. Heart and circulatory physiology. 2004; 287:H2612-2618. [PubMed: 15256376]

28. Zucker IH, Schultz HD, Li YF, Wang Y, Wang W, Patel KP. The origin of sympathetic outflow in heart failure: The roles of angiotensin ii and nitric oxide. Prog Biophys Mol Biol. 2004; 84:217232. [PubMed: 14769437]

29. Kim JK, Sala-Mercado JA, Hammond RL, Rodriguez J, Scislo TJ, O'Leary DS. Attenuated arterial baroreflex buffering of muscle metaboreflex in heart failure. American journal of physiology. Heart and circulatory physiology. 2005; 289:H2416-2423. [PubMed: 16055513]

30. Narkiewicz K, Pesek CA, van de Borne PJ, Kato M, Somers VK. Enhanced sympathetic and ventilatory responses to central chemoreflex activation in heart failure. Circulation. 1999; 100:262-267. [PubMed: 10411850]

31. Di Vanna A, Braga AM, Laterza MC, Ueno LM, Rondon MU, Barretto AC, Middlekauff HR, Negrao CE. Blunted muscle vasodilatation during chemoreceptor stimulation in patients with heart failure. American journal of physiology. Heart and circulatory physiology. 2007; 293:H846-852. [PubMed: 17434973]

32. Indolfi C, Maione A, Volpe M, Rapacciuolo A, Esposito G, Ceravolo R, Rendina V, Condorelli M, Chiariello M. Forearm vascular responsiveness to alpha 1- and alpha 2-adrenoceptor stimulation in patients with congestive heart failure. Circulation. 1994; 90:17-22. [PubMed: 7913001]

33. Hammond RL, Augustyniak RA, Rossi NF, Churchill PC, Lapanowski K, O’Leary DS. Heart failure alters the strength and mechanisms of the muscle metaboreflex. American journal of physiology. Heart and circulatory physiology. 2000; 278:H818-828. [PubMed: 10710350]

34. Amann M, Calbet JA. Convective oxygen transport and fatigue. J Appl Physiol. 2008; 104:861870. [PubMed: 17962570]

35. Amann M, Dempsey JA. Locomotor muscle fatigue modifies central motor drive in healthy humans and imposes a limitation to exercise performance. The Journal of physiology. 2008; 586:161-173. [PubMed: 17962334] 
36. Poole DC, Hirai DM, Copp SW, Musch TI. Muscle oxygen transport and utilization in heart failure: Implications for exercise (in)tolerance. American journal of physiology. Heart and circulatory physiology. 2012; 302:H1050-1063. [PubMed: 22101528]

37. Wilson JR, Martin JL, Ferraro N. Impaired skeletal muscle nutritive flow during exercise in patients with congestive heart failure: Role of cardiac pump dysfunction as determined by the effect of dobutamine. Am J Cardiol. 1984; 53:1308-1315. [PubMed: 6711433]

38. Maskin CS, Forman R, Sonnenblick EH, Frishman WH, LeJemtel TH. Failure of dobutamine to increase exercise capacity despite hemodynamic improvement in severe chronic heart failure. Am J Cardiol. 1983; 51:177-182. [PubMed: 6849256]

39. Wang HJ, Li YL, Gao L, Zucker IH, Wang W. Alteration in skeletal muscle afferents in rats with chronic heart failure. The Journal of physiology. 2010; 588:5033-5047. [PubMed: 21041525]

40. Smith SA, Mitchell JH, Naseem RH, Garry MG. Mechanoreflex mediates the exaggerated exercise pressor reflex in heart failure. Circulation. 2005; 112:2293-2300. [PubMed: 16216976] 

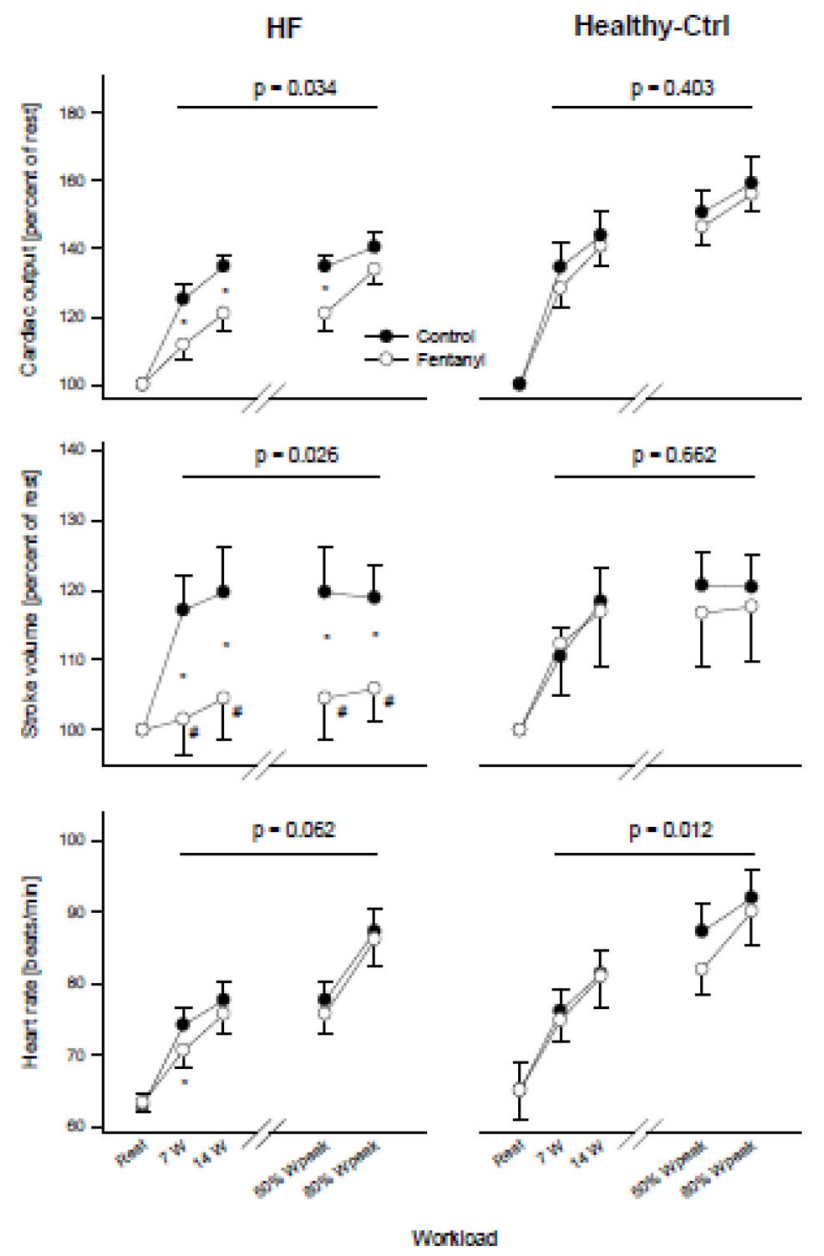

Figure 1.

Cardiac-related variables at rest and during exercise. The $\mathrm{p}$-value indicates a significant main effect of fentanyl. *p<0.05, ${ }^{*}$ not different from rest 

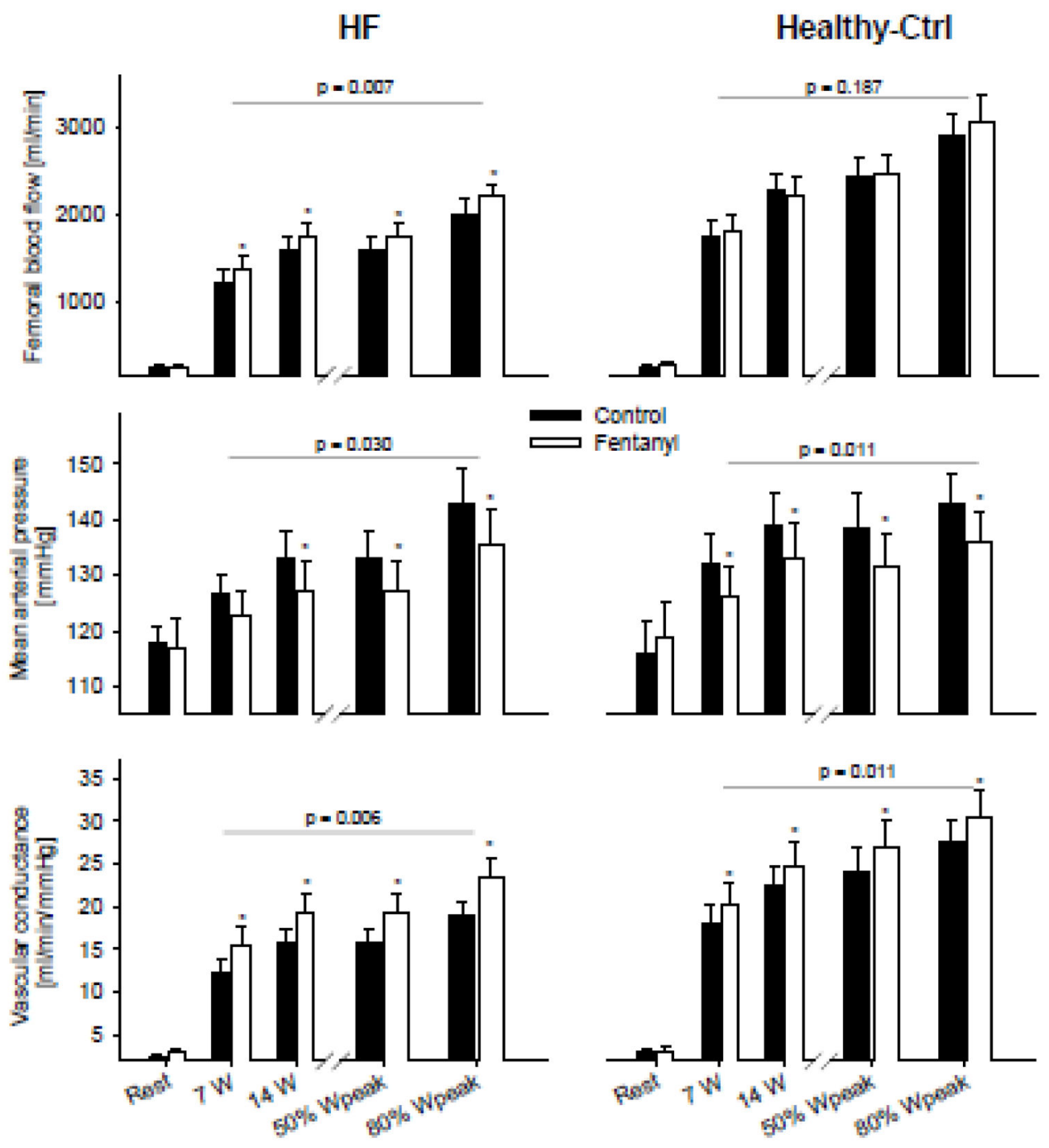

Workload

Figure 2.

Hemodynamic responses at rest and during the final minute of exercise. The p-value indicates the overall main effect of fentanyl. ${ }^{*} \mathrm{p}<0.05$ 


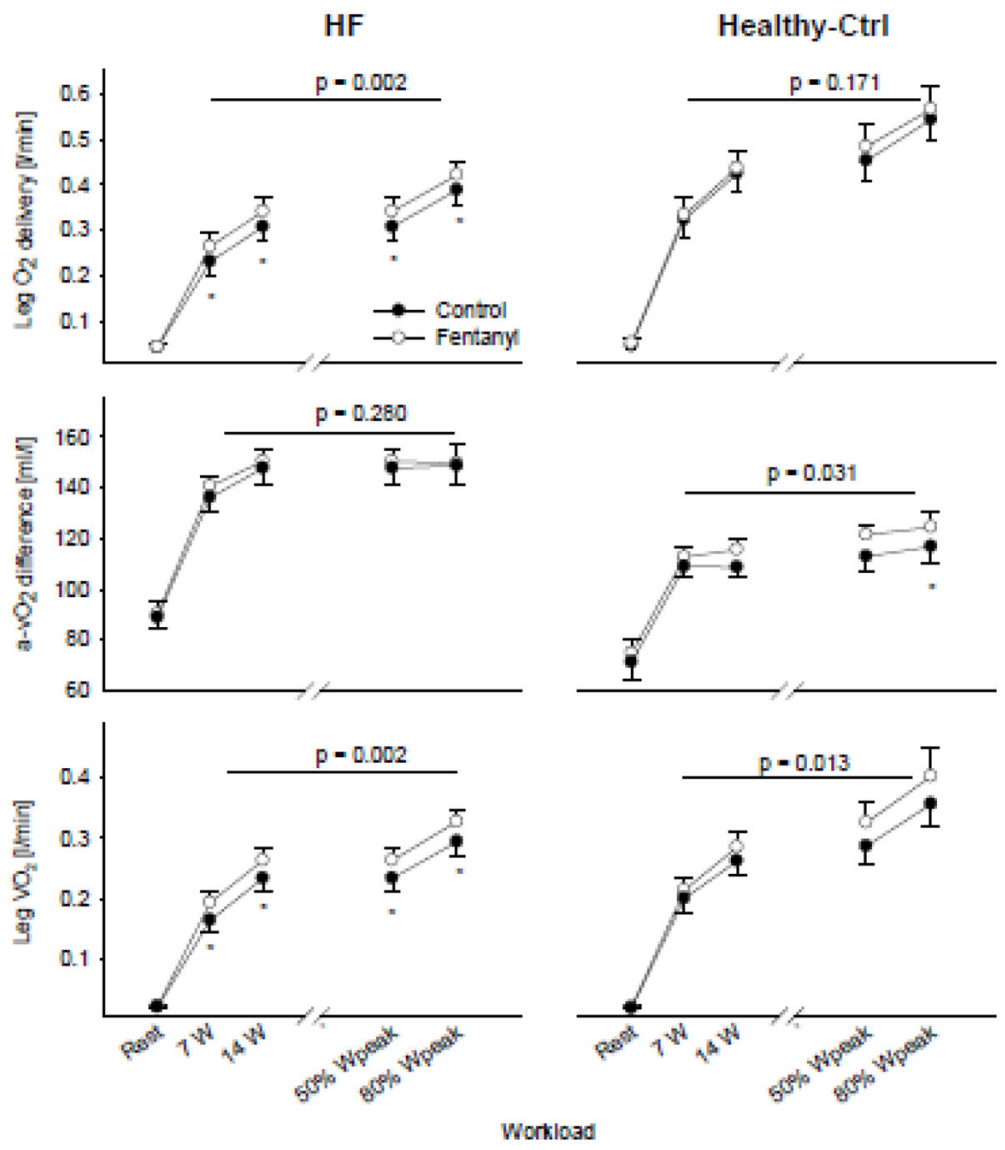

Figure 3.

Leg $\mathrm{O}_{2}$ supply and demand at rest and during the final minute of exercise. The p-value indicates the overall main effect of fentanyl. ${ }^{*} \mathrm{p}<0.05$ 


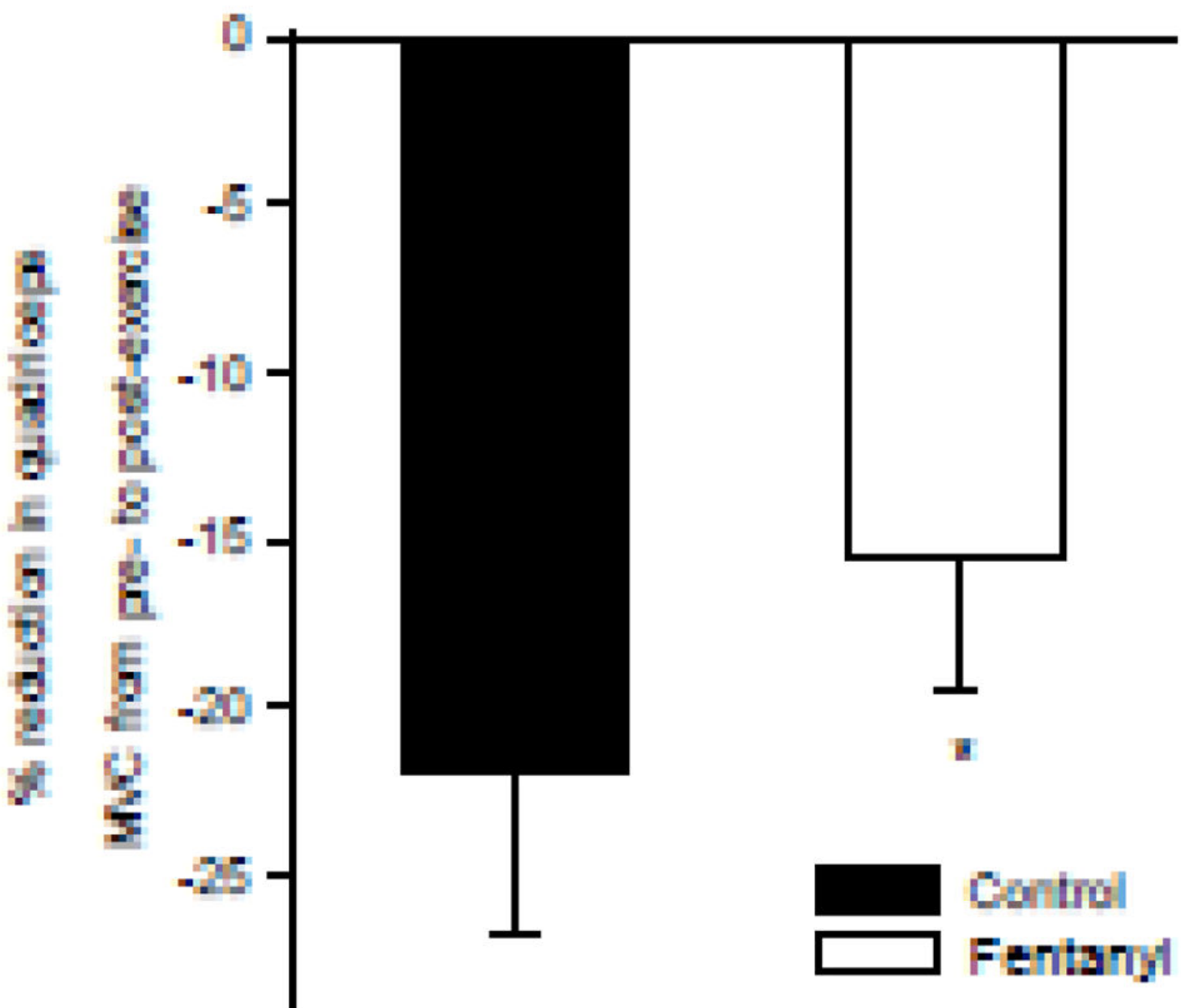

Figure 4.

Exercise-induced reduction in maximal quadriceps voluntary concentration force (MVC) in patients with HF. $\mathrm{N}=5 ; * \mathrm{P}<0.01$ 


\section{Table 1}

Subject characteristics

\begin{tabular}{lcc}
\hline \multicolumn{3}{c}{ Demographics } \\
\hline & HF & Healthy-Ctrl \\
\hline Age, yrs & $64 \pm 3$ & $70 \pm 3$ \\
Height, cm & $177 \pm 2$ & $178 \pm 2$ \\
Weight, kg & $92 \pm 5$ & $87 \pm 4$ \\
Body mass index, kg/m² & $29 \pm 1$ & $27 \pm 1$ \\
Left ventricular ejection fraction, \% & $27 \pm 3$ & \\
Ischemic cardiomyopathy & $7 / 9$ & \\
Non-ischemic cardiomyopathy & $2 / 9$ & \\
NYHA Class II & $9 / 9$ & \\
Diabetic & $2 / 9$ & 19 \\
& & \\
\hline Beta-blocker & Medications & \\
ACE-Inhibitor & $9 / 9$ & $0 / 9$ \\
Angiotensin Receptor Blocker & $7 / 9$ & $0 / 9$ \\
Aldosterone antagonist & $2 / 9$ & $0 / 9$ \\
Statin & $6 / 9$ & $0 / 9$ \\
Diuretic & $9 / 9$ & $0 / 9$ \\
Antiarrythmic & $7 / 9$ & $0 / 9$ \\
Calcium channel-blocker & $4 / 9$ & $0 / 9$ \\
Alpha-blocker & $0 / 9$ & $0 / 9$ \\
\hline & $0 / 9$ & $0 / 9$ \\
\hline
\end{tabular}

Data are presented as mean \pm SE or as $n$ out of all 9 participants (n/9) 


\begin{tabular}{|c|c|c|c|c|c|c|c|c|c|c|c|c|c|c|c|c|c|c|c|c|c|c|c|}
\hline & & $\begin{array}{cc}0 & 0 \\
0 \\
0 \\
0 & 0 \\
0 & 0 \\
0\end{array}$ & 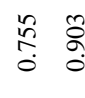 & & ठ̊. & ิే & $\frac{a}{3} \cdot \frac{m}{3}$ & ठి & $\begin{array}{l}\frac{\partial}{\partial} \\
\dot{0}\end{array}$ & तิ & : & ఫે & {$\left[\begin{array}{l}0 \\
0 \\
0\end{array}\right.$} & 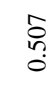 & : & స్రి & $\stackrel{\substack{1 \\
0}}{0}$ & :̊. & $\stackrel{m}{a}$ & శ్ & 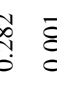 & $\bar{\delta}$ & ర్లి \\
\hline$z^{3}$ & 氞 & 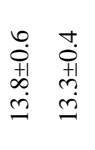 & 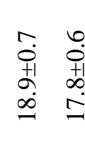 & 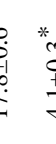 & 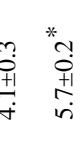 & $\begin{array}{l}7 \\
0 \\
5\end{array}$ & 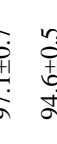 & 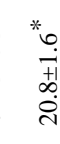 & $\frac{{ }^{*}}{+}$ & 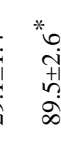 & $\begin{array}{l}\infty \\
\stackrel{\infty}{+} \\
\infty \\
\infty \\
\infty\end{array}$ & $\begin{array}{l}9 \\
\dot{+1} \\
\dot{2}\end{array}$ & $\stackrel{+}{\stackrel{+}{+1}}$ & 市 & 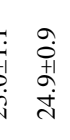 & $\begin{array}{l}\stackrel{+}{+} \\
\stackrel{+}{+} \\
\dot{+}\end{array}$ & 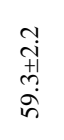 & 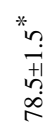 & 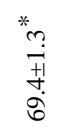 & 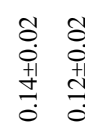 & 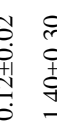 & & $\begin{array}{l}0 \\
\vdots \\
0 \\
0 \\
\vdots \\
\vdots\end{array}$ \\
\hline$\stackrel{\circ}{\circ}$ & $\Xi$ & 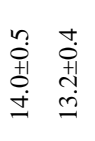 & 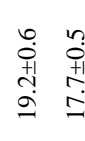 & 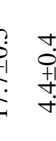 & 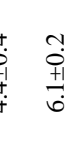 & $\begin{array}{l}5 \\
0 \\
1 \\
0 \\
0\end{array}$ & 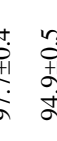 & $\begin{array}{l}0 \\
\text { i } \\
+1 \\
\text { ì }\end{array}$ & $\begin{array}{l}\dot{\bar{i}} \\
\dot{0} \\
\dot{m}\end{array}$ & 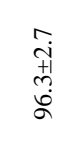 & 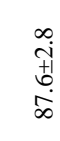 & 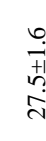 & 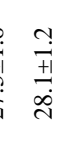 & $\begin{array}{l}\hat{0} \\
\text { iे } \\
\text { in } \\
\text { in }\end{array}$ & 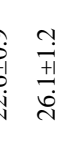 & $\begin{array}{l}m \\
\stackrel{m}{+} \\
+1 \\
\infty \\
\stackrel{R}{R}\end{array}$ & $\begin{array}{l}n \\
i \\
\pm \\
i \\
i n\end{array}$ & $\frac{\substack{++1 \\
\stackrel{+1}{i}}}{i}$ & $\begin{array}{l}3 \\
\dot{+1} \\
n \\
03 \\
6\end{array}$ & 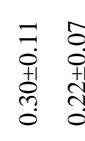 & & 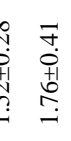 & \\
\hline$\stackrel{\text { ñ }}{\tilde{E}}$ & 勇 & 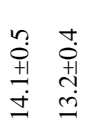 & 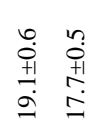 & 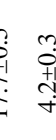 & 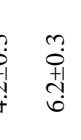 & $\begin{array}{l}7 \\
0 \\
0 \\
0 \\
0\end{array}$ & 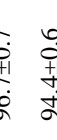 & $\stackrel{{ }^{*}+}{\stackrel{+}{+}}$ & 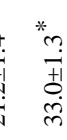 & 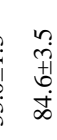 & $\begin{array}{l}\text {. } \\
+1 \\
\infty \\
\infty \\
\infty\end{array}$ & $\begin{array}{l}n \\
+1 \\
\infty \\
0 \\
i \\
m\end{array}$ & $\frac{0}{ \pm}$ & $\begin{array}{l}0 \\
\text { ì } \\
\text { iे } \\
\text { in }\end{array}$ & 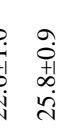 & $\begin{array}{l}n \\
+ \\
+1 \\
\vdots \\
8\end{array}$ & 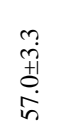 & 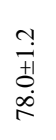 & 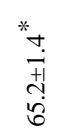 & \begin{tabular}{ll} 
& \multicolumn{1}{c}{} \\
0 & 0 \\
01 & 0 \\
0 & 0 \\
0 & 0 \\
0 & 0 \\
0
\end{tabular} & $\begin{array}{cc}0 & 0 \\
0 & 0 \\
11 & 1 \\
0 & 0 \\
0 & 0\end{array}$ & 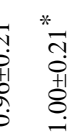 & $\begin{array}{c}* \\
1 \\
7 \\
+1 \\
0 \\
0 \\
0 \\
0\end{array}$ \\
\hline 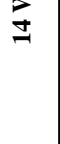 & $\Xi$ & 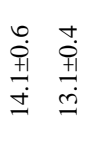 & 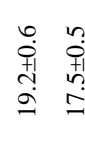 & 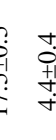 & 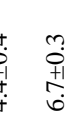 & 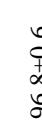 & 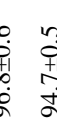 & 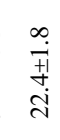 & 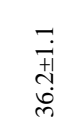 & 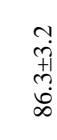 & $\begin{array}{l}0 \\
+ \\
+1 \\
+ \\
\infty \\
\infty\end{array}$ & $\begin{array}{l}+ \\
\dot{+} \\
\dot{0} \\
\dot{m}\end{array}$ & $\frac{n}{\frac{n}{4}}$ & $\stackrel{\hat{i}}{\stackrel{+}{+}}$ & 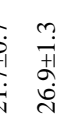 & 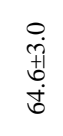 & $\begin{array}{l}\frac{a}{+} \\
\text { in } \\
\text { in }\end{array}$ & 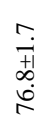 & $\begin{array}{l}\vec{i} \\
\stackrel{+1}{i} \\
\text { d }\end{array}$ & 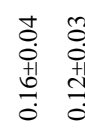 & & 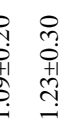 & $\begin{array}{l}\text { I1 } \\
\text { 11 } \\
\text { đั. }\end{array}$ \\
\hline 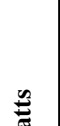 & 勇 & 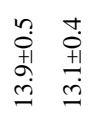 & 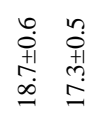 & 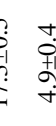 & 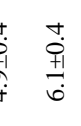 & 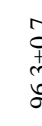 & 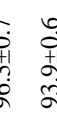 & $\begin{array}{l}\stackrel{0}{+} \\
+1 \\
\dot{+}\end{array}$ & $\begin{array}{l}\infty \\
\dot{+} \\
\dot{0} \\
\dot{m}\end{array}$ & $\begin{array}{l}\vec{j} \\
\dot{0} \\
0 \\
\infty \\
\infty\end{array}$ & $\begin{array}{l}0 \\
+ \\
+ \\
+ \\
\dot{+} \\
\end{array}$ & $\begin{array}{l}\text { Tे } \\
\text { ثे } \\
\text { ते }\end{array}$ & $\begin{array}{l}+ \\
\vdots \\
0 \\
0 \\
0\end{array}$ & $\begin{array}{l}\circ \\
\stackrel{+}{+1} \\
\text { ì } \\
\text { in }\end{array}$ & 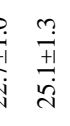 & $\begin{array}{l}\infty \\
\dot{j} \\
+1 \\
\dot{b} \\
\dot{b}\end{array}$ & $\begin{array}{l}n \\
i \\
+1 \\
0 \\
\infty \\
c\end{array}$ & $\begin{array}{l}n \\
\stackrel{n}{+1} \\
m \\
⿱ 亠 䒑 \\
i\end{array}$ & 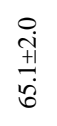 & $\begin{array}{ll}\tilde{O} & \tilde{0} \\
0 & 0 \\
+11 & + \\
= & 0 \\
0 & 0\end{array}$ & & 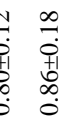 & 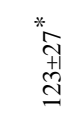 \\
\hline$\pi$ & $\Xi$ & 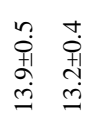 & 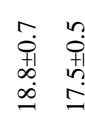 & 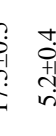 & 柋 & $\begin{array}{l}0 \\
0 \\
d \\
d\end{array}$ & 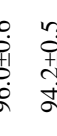 & 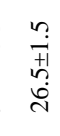 & 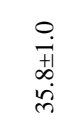 & $\begin{array}{c}\stackrel{2}{2} \\
\stackrel{+}{+} \\
\stackrel{2}{R}\end{array}$ & $\begin{array}{c}m \\
\stackrel{+}{0} \\
\dot{\infty} \\
\dot{\infty}\end{array}$ & 薄 & 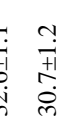 & $\begin{array}{l}2 \\
0 \\
+1 \\
\text { in }\end{array}$ & 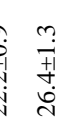 & \begin{tabular}{l}
0 \\
$\dot{+1}$ \\
\multirow{1}{n}{} \\
$i n$ \\
$i n$
\end{tabular} & $\begin{array}{l}\text { ì } \\
\text { i⿱ } \\
0 \\
\text { in }\end{array}$ & $\begin{array}{l}+ \\
\stackrel{+}{+} \\
\substack{i \\
i}\end{array}$ & 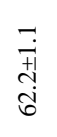 & $\begin{array}{ll}0 & 0 \\
0 & 0 \\
\text { in } & 0 \\
= & 0 \\
0 & 0\end{array}$ & & 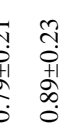 & $\begin{array}{l}\hat{T} \\
\text { in } \\
\text { n. }\end{array}$ \\
\hline & 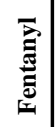 & 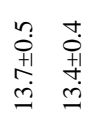 & $\begin{array}{cc}0 & n \\
0 & 0 \\
+1 & +1 \\
n & 0 \\
0 & 0\end{array}$ & 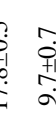 & 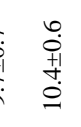 & $\begin{array}{ll}n \\
0 \\
c \\
c\end{array}$ & 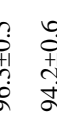 & $\begin{array}{l}\hat{i} \\
+1 \\
\stackrel{\sigma}{\sigma}\end{array}$ & $\begin{array}{l}0 \\
i \\
+1 \\
\infty \\
\dot{0} \\
\dot{n}\end{array}$ & \begin{tabular}{l}
0 \\
$\stackrel{0}{1}$ \\
\multirow{1}{0}{} \\
$\stackrel{0}{i}$
\end{tabular} & $\begin{array}{l}0 \\
+1 \\
+1 \\
\infty \\
\infty\end{array}$ & 芦 & 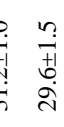 & 市 & 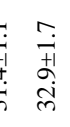 & $\begin{array}{l}\infty \\
\dot{+1} \\
\stackrel{+}{n} \\
\dot{+}\end{array}$ & $\begin{array}{l}\stackrel{0}{i} \\
\text { it } \\
\text { g. }\end{array}$ & $\begin{array}{l}\hat{O} \\
\text { H } \\
\stackrel{+}{+}\end{array}$ & 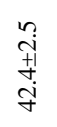 & \begin{tabular}{ll} 
& \multicolumn{1}{c}{} \\
0 & $\vdots$ \\
01 & + \\
01 & +1 \\
0 & 0 \\
0 & 0
\end{tabular} & $\begin{array}{ll}0 & 0 \\
0 & 0 \\
01 & + \\
0 \\
0 \\
0 \\
0 \\
0 \\
0\end{array}$ & 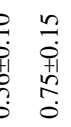 & $\stackrel{\sim}{+1}$ \\
\hline & $\Xi$ & $\begin{array}{ll}0 & m \\
0 & 0 \\
01 & 1 \\
0 & 1 \\
0 & 0 \\
& 0\end{array}$ & 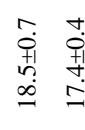 & 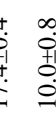 & 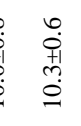 & $\begin{array}{l}b \\
0 \\
1 \\
b \\
b\end{array}$ & 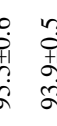 & $\begin{array}{l}\hat{i} \\
+1 \\
m \\
\vec{n}\end{array}$ & \begin{tabular}{l}
0 \\
iे \\
\multirow{+1}{*}{} \\
in
\end{tabular} & $\begin{array}{l}\text { ì } \\
+1 \\
\text { in } \\
\stackrel{n}{2}\end{array}$ & $\begin{array}{l}n \\
i \\
+ \\
0 \\
0 \\
i\end{array}$ & 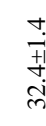 & 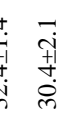 & $\begin{array}{l}\infty \\
0 \\
0 \\
+1 \\
0 \\
0 \\
0\end{array}$ & 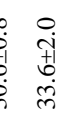 & 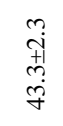 & $\begin{array}{l}n \\
\frac{n}{1} \\
0 \\
\text { in } \\
m\end{array}$ & $\begin{array}{l}\infty \\
\text { i } \\
+1 \\
0 \\
\dot{j} \\
\dot{q}\end{array}$ & $\begin{array}{l}+ \\
\tilde{d} \\
+1 \\
o \\
\dot{q}\end{array}$ & $\begin{array}{ll}\overrightarrow{0} & 0 \\
\dot{0} & \vdots \\
+1 & +1 \\
0 & 0 \\
0 & 0 \\
0 & 0\end{array}$ & & 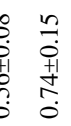 & $\begin{array}{l}\frac{y}{+1} \\
+1 \\
\frac{1}{2}\end{array}$ \\
\hline & & 岌 & 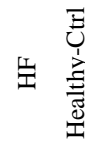 & 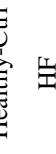 & 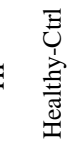 & 㘳 & 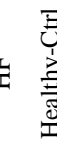 & 至 & 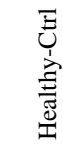 & 岌 & $\begin{array}{l}\text { E } \\
\text { 京 } \\
\text { 吾 } \\
\text { 至 }\end{array}$ & 圼 & 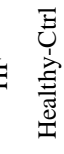 & 炷 & 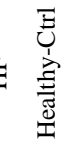 & 告 & $\begin{array}{l}\vec{E} \\
\text { 交 } \\
\text { 吾 } \\
\text { 至 }\end{array}$ & 岳 & 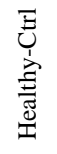 & & & 壱 & t \\
\hline & & $\begin{array}{l}\text { 해 } \\
\text { 㱟 }\end{array}$ & 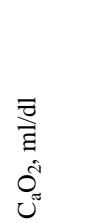 & $\begin{array}{l}7 \\
0 \\
0 \\
0\end{array}$ & & & & $\begin{array}{l}8 \\
0 \\
0 \\
0\end{array}$ & & 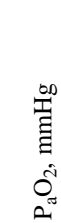 & & s & is & $\alpha^{2}$ & & 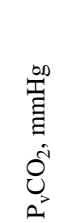 & & 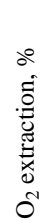 & & 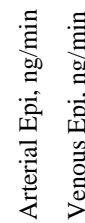 & 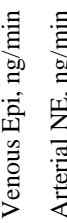 & 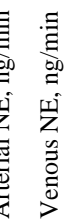 & . \\
\hline
\end{tabular}


